\title{
Evaluation of Urmia’s Imam Khomeini Hospital Regarding Passive Defense Criteria in 2017
}

\author{
Shadi Nouriaghdam ${ }^{1}$, Zohreh Ghaffarzadeh ${ }^{1}$, Elahe Shakeri ${ }^{2}$ and Saeed Hosseinpoor (iD ${ }^{1,}$ \\ ${ }^{1}$ Department of Environmental Health Engineering, School of Public Health, Urmia University of Medical Sciences, Urmia, Iran \\ ${ }^{2}$ Department of Urban Engineering, Payame Noor University, Urmia Iran \\ "Corresponding author: Department of Environmental Health Engineering, School of Public Health, Urmia University of Medical Sciences, Urmia, Iran. Email: \\ saeed.hosseinpooreng61@yahoo.com
}

Received 2018 December 02; Revised 2018 December 10; Accepted 2018 December 11.

\begin{abstract}
Background: During the wars and natural disasters, cities are threatened and suffer a lot, so employing the principles of passive defense in order to save people concerns authorities and policymakers. Urmia is the capital of Azarbaijan-Gharbi province and it has a strategic, political, economic and hygienic importance due to its common border with some countries. Therefore, numerous potential dangers threaten national security and independence of this region. Strengthening buildings, especially, health care centers and hospitals have a key role in mental safety and peace of the public.

Objectives: This study aimed to evaluate Imam Khomeini Hospital based on passive defense principles including design, architecture and mode of locating.

Methods: The current research was a descriptive analytical study. Passive defense indicators were extracted from the Iranian building regulations (vol. 21). The data were collected through a self-designed checklist according to 16 criteria through interviews and field observations. Data were analyzed in Excel $^{\circledR}$ and figures were obtained from Google Map.

Results: Considering passive defense requirements, 75\% of the studied indicators in Urmia's Imam Khomeini Hospital were rendered defenseless. Four eligible indicators included firefighting system, entry and exit doors, emergency power system, and access to the fire station.

Conclusions: It is essential to observe these requirements and build double-purpose hospitals to reduce vulnerability, financial and health damage, and provide health services in critical situations.
\end{abstract}

Keywords: Hospital Locating, Passive Defense, Urmia, Design

\section{Background}

Over the past century, the development of technology and military equipment has led to the increase in wars and casualties (1). Therefore, the strategies for fighting and defense has also changed in international politics (2). As a result, in addition to trying to prevent the war, authorities use passive defense to reinforce the stamina of urban parties (1). Natural disasters and wars can be dealt with through active or passive defense. Active defense is a direct defensive method in which military equipment and weapons are used, while the passive defense is an indirect defense method that prevents or minimizes damage to infrastructures. The latter is usually used during peacetime (3). Indirect combat in the war has also been common in the past, for instance, digging a ditch in the Prophet's wars is an exemplar of passive defense $(1,2)$. In fact, passive defense strategies are used to complete the defense chain in the crisis time (http://www.akairan.com/elmi/maghalatsanaye/111016074221.html).

Public places are in the high priority list for implementing passive defense in the infrastructure of the country because people more often gather in these places and seek shelter at the time of war or natural disasters. Due to their nature and usage, they serve a large number of people, so if the principles of passive defense are not met, there will be a catastrophic loss at the time of disasters or enemy attacks (4). Protective levels of different places are determined based on their usage characteristics. Accordingly, public places are classified into three categories of sensitive, vital and important (5). Among public places, hospitals have a substantial role in preventing and reducing the risk of abnormal accidents by creating environmental safety and protecting patients, employees or visitors (6). Therefore, it is necessary to assess the principles of passive 
defense and the need to protect these vital places because any damage to these places can endanger the public peace (5). The setting of research was in Urmia city located in Azarbaijan-Gharbi province in the northwest of Iran. It is limited from North to Azerbaijan and Turkey, from east to Turkey and Iraq, from East to Azarbaijan-Sharghi and Zanjan provinces, and from South to Kurdistan province. Having common borders with three countries has made the location of this city special. Urmia has twelve hospitals, of which we studied Imam Khomeini Hospital. It is one of the most important hospitals in the province with a high bed occupancy rate and more than 20 years of experience at national and international levels.

\section{Objectives}

The present study evaluated Imam Khomeini Hospital in terms of compliance with standard safety indicators of location and design based on the principles of passive defense.

\section{Methods}

The present descriptive study was conducted in Urmia's Imam Khomeini Hospital in 2017. A researcher-made checklist was developed based on 16 indicators extracted from various studies which evaluated by two experts were used for data extraction $(1,2,4,7,8)$. The research data, including the hospital data, were collected through observation and interviews with the staff of technical office at Imam Khomeini Hospital. The obtained data were analyzed in Excel ${ }^{\circledR}$ software, and figures of vital places were extracted from Google Map.

\subsection{Urmia's Strategic Places}

Vital centers are places where their complete or partial destruction leads to chaos, crises, and serious damage to the systems of politics, guidance, control and command, production and economics, support, communication, society, and defense. These centers include the Governor's office, municipality, hospitals, grand bazaar, telecommunication offices, and police department whose locations are marked in Figure 1 in relation to Imam Khomeini Hospital in Urmia.

Sensitive centers are places where their complete or partial destruction at regional level leads to chaos, crises, and serious damage to the systems of politics, guidance, control and command, production and economics, support, communication, society, and defense. These include filling stations; power, water and gas transmission networks, and bridges (Figure 2).
Important centers are places where their complete or partial destruction at local level leads to chaos, crises, and serious damage to the systems of politics, guidance, control and command, production and economics, support, communication, society, and defense. These include gas stations, Bazaar Park, and the prison (Figure 3).

\section{Results and Discussion}

In the present study, 16 indicators of passive defense standard were investigated in Urmia's Imam Khomeini Hospital. Just four of the studied indicators (25\%) were eligible (Figure 4). The details are presented in Table 1.

In Urmia's Imam Khomeini Hospital, most wards were located and concentrated in the main building (Table 2). According to the national regulations of construction, the wards should be constructed in dispersion because the concentration of equipment and assets in one location increases the possibility of being targeted, leads to difficulties in rapid evacuation, increases the risk and entails destructive consequences (7). Furthermore, in the studies conducted in Imam Reza and Razavi hospitals in Mashhad, the concentration of most wards in one building was described as a weak point (1).

The surrounding area of Urmia's Imam Khomeini Hospital was not enough for total camouflage of the building. The presence of vegetation around the hospital could have a bilateral efficiency. First, it would be in harmony with the surrounding area and make it difficult to identify. Second, its efficacy is related to the creation of buffer space that reduced the damage caused by the explosion (7). Despite the presence of a large open space around the Razavi Hospital, a lack of sufficient green space was considered a weak point for this hospital, while the strong point of Imam Reza Hospital was the presence of sufficient green space around it (1).

Urmia's Imam Khomeini Hospital had three main exits and eight emergency egress doors. In accordance with volume 21 of the Iranian building regulations, the risk of fall at the time of collapse is within one-third of building's height, so the safe distance from the building is more than that. For a large residential complex with more than 200 units, the standard number of entries is more than three (7). Thus the number of access doors for Imam Khomeini Hospital was eligible.

Open space design of Imam Khomeini Hospital and its components do not hinder normal activities under emergency conditions. National construction regulations have set the minimum requirements for building open space (7). Regarding this indicator, Imam Khomeini Hospital did not have enough space for temporary lodging of people in emergency situations. 

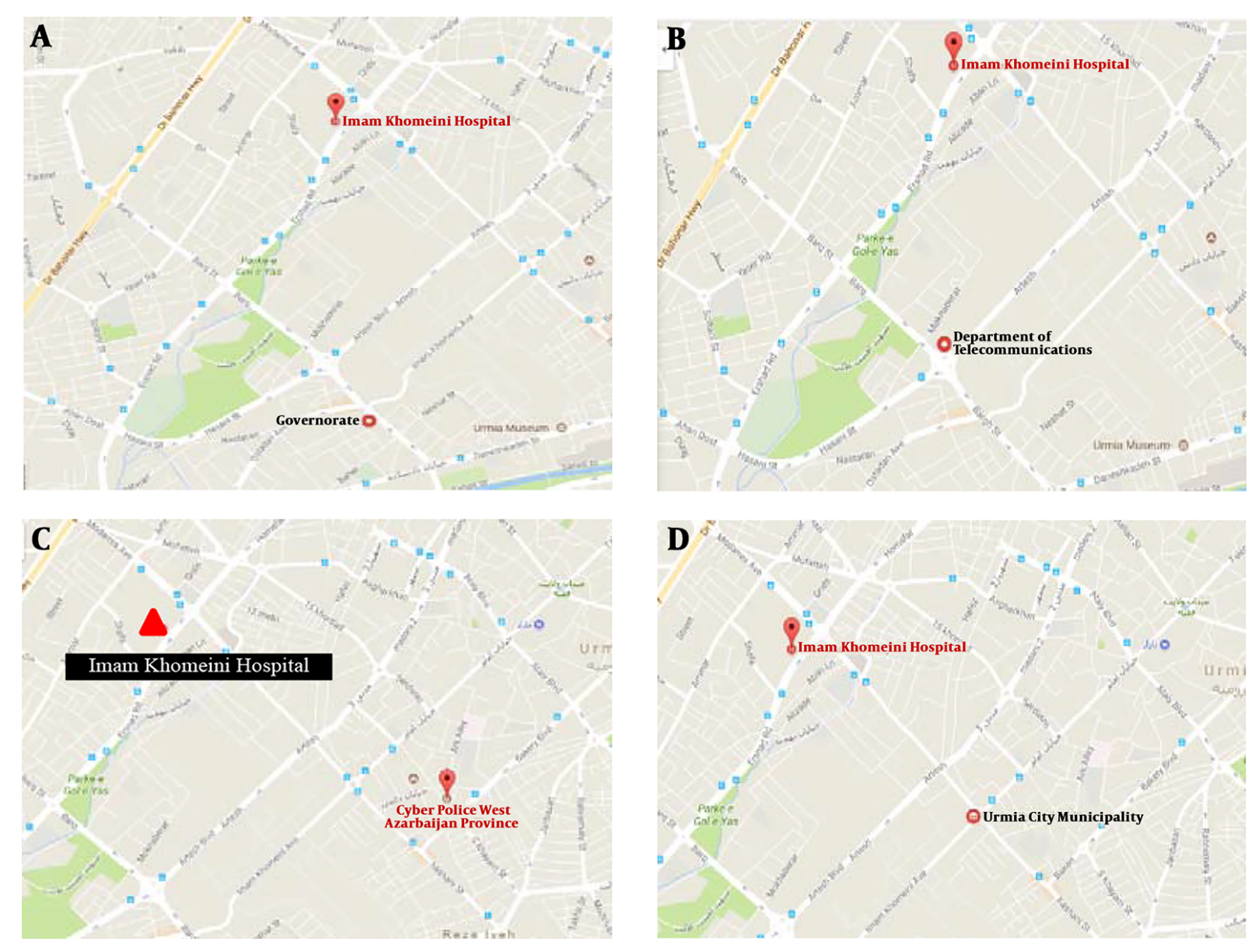

Figure 1. Location of vital centers in Urmia city compared to Imam Khomeini Hospital. A, governorate; B, telecommunications; C, police department; D, municipality.

Based on the national regulations, dangerous and military activities should not be conducted within a $1000 \mathrm{~m}$ radius around the hospital (7). However, the police headquarters of Azarbaijan-Gharbi province was located about $220 \mathrm{~m}$ away from Imam Khomeini Hospital. Other places such as the library and park were located $40 \mathrm{~m}$ and 120 $m$ away from the hospital, respectively. Savadkoohifar and Zokai Fateh considered the presence of a park around the hospital positive for establishing a mobile hospital during emergency situations (8). Furthermore, a study on Langroud city suggested designing large buildings flexible and multipurpose for critical situations (4). Since Urmia's Central Library is located across from Imam Khomeini Hospital, it can be used for temporary lodging if its building is sustainable enough.

The facade of Imam Khomeini Hospital is made of travertine stone which can be distinguished from its surrounding environment. Considering the role of materials in the sustainability of external walls, reducing the explo- sion waves, and thermal radiation of the building, cement plaster is better than brick facade for exterior walls. Furthermore, loose elements should be removed from the facade of buildings with the first and second levels of importance. Light materials such as wood, plastic, aluminum, polymer, and composite materials can be used for decorating the facade. Glass should not be used in the facade of buildings, as much as possible, with the first and second levels of importance (7). According to a study conducted in Mashhad, the facade of the building was eligible because it was distinguishable from the surrounding area (1). Piri et al. emphasized the use of safety glass and less use of glass in the facade of the building, as one of the main objectives of passive defense, to provide safety against throwing glass into the building (9).

The main building of Imam Khomeini Hospital has five floors with a height of $25 \mathrm{~m}$. The clinic has 2 floors with a height of $9 \mathrm{~m}$, while the amphitheater has 2 floors with a height of $12 \mathrm{~m}$. In a study by Hasani et al. in Mashhad, the 

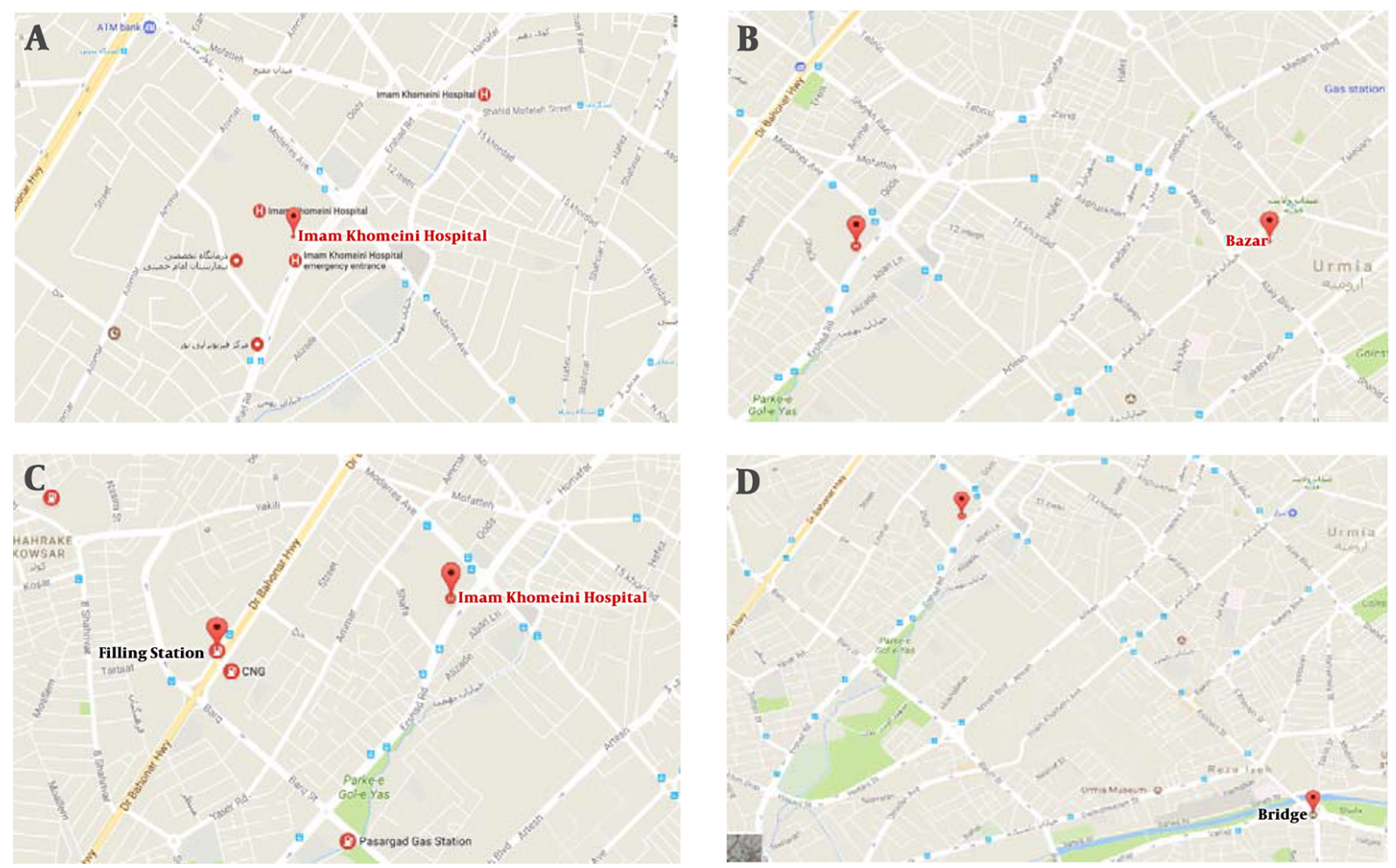

Figure 2. Location of sensitive centers in Urmia city compared to Imam Khomeini Hospital. A, hospital; B, bazaar; C, filling station; D, bridge.
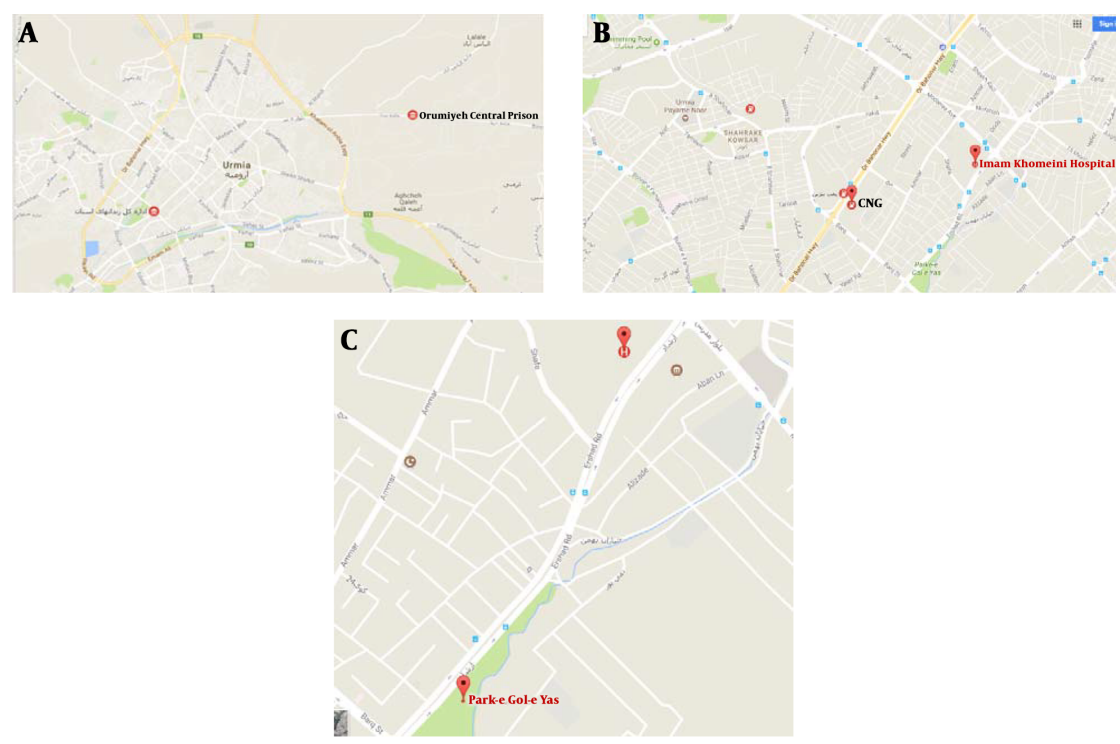

Figure 3. Location of important centers in Urmia city compared to Imam Khomeini Hospital. A, prison; B, gas station; C, park.

height of Razavi and Imam Reza hospitals was counted as a weak point because their height increased the likelihood of being targeted (1).
Another indicator to be considered in hospital construction is the shelter. Shelter design can be singlepurpose or multi-purpose. The protection level of each 


\begin{tabular}{|c|c|c|}
\hline \multicolumn{2}{|l|}{ Criteria } & Status in Urmia's Imam Khomeini Hospital \\
\hline \multicolumn{2}{|c|}{ Firefighting system } & Eligible \\
\hline \multicolumn{2}{|c|}{ Entry and exit doors } & Eligible \\
\hline \multicolumn{2}{|c|}{ Emergency power system } & Eligible \\
\hline \multicolumn{2}{|c|}{ Access to the fire station } & Eligible \\
\hline \multicolumn{2}{|c|}{ Decentralization of different parts of a building } & Not eligible \\
\hline \multicolumn{2}{|c|}{ Vacant space around the hospital } & Not eligible \\
\hline \multicolumn{2}{|c|}{ Depth and height of the hospital building } & Not eligible \\
\hline \multicolumn{2}{|c|}{ Existence of shelter } & Not eligible \\
\hline \multicolumn{2}{|c|}{ The exterior of the building of the hospital } & Not eligible \\
\hline \multicolumn{2}{|c|}{ Stockroom } & Not eligible \\
\hline \multicolumn{2}{|c|}{ Helicopter landing pad } & Not eligible \\
\hline \multicolumn{2}{|c|}{ Equipment for the installation of mobile hospital } & Not eligible \\
\hline \multicolumn{2}{|c|}{ Car parking } & Not eligible \\
\hline \multicolumn{2}{|c|}{ Location in the city center and access to extreme roads } & Not eligible \\
\hline \multicolumn{2}{|c|}{ Hazardous and military applications } & Not eligible \\
\hline \multicolumn{2}{|c|}{ High intersections around the hospital } & Not eligible \\
\hline Floors & Wards & \\
\hline 5 & Oncology, internal, pulmonary diseases, and digestive diseases, MICU & \\
\hline 4 & Neurosurgery, nephrology, NICU & \\
\hline 3 & Urology, kidney transplant, ENT, surgery room B, surgery room C & \\
\hline 2 & Surgery for men and women, surgery room A, internal neuronics, SICUA, SICUB & \\
\hline 1 & Orthopedic, laboratory, blood bank, radiology, sonography, CT scan & \\
\hline Ground & $\begin{array}{l}\text { Emergency, trauma, general internal, dialysis, burns, GICU, ecocardiography, fit } \\
\text { spirometry }\end{array}$ & hoscopy, endoscopy, medical reception and records, \\
\hline
\end{tabular}

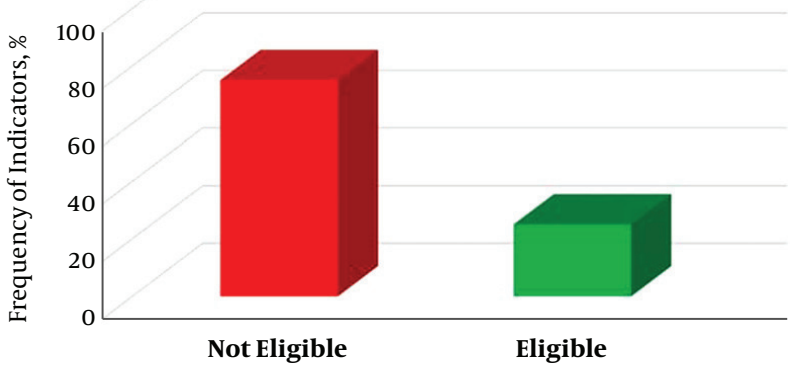

Eligibility of Passive Defense Indicators

$\overline{\text { Figure 4. Conformity ratio of passive defense indicators to the standards in Urmia's }}$ Imam Khomeini Hospital

J Clin Res Paramed Sci. 2018; 7(2):e86989. shelter varies according to the existing threats. In buildings with the first level of importance, a vacant space with higher sustainability should be designed in addition to the multi-purpose shelter space and its location should be accessible to the public (7). Imam Khomeini Hospital does not have a specific shelter.

The use of sprinkler system and standpipe is the best solution to control fire. Fire extinguishers should be located in safe places with easy access (7). In the study of Imam Khomeini Hospital, it was found that, there were fire hydrants and fire extinguishing systems, but they were not smart. International standards suggest having a fire station within $5 \mathrm{~km}$ radius, such that the maximum time to reach the fire site should be 3 to 5 minutes (1). The distance between Imam Khomeini Hospital and fire station 1, the nearest station to Imam Khomeini Hospital located in Urmia's Madani intersection, was less than $5 \mathrm{~km}$. 
Providing air access to the hospital and installing helipad are essential to rapid transmission of the injured and transfer of equipment for establishing a mobile hospital in emergency situations. Hospital signs should also be sufficient to quickly guide people to use exit doors for rapid evacuation. Evacuation of crowds in emergency situations requires signs and lights (10). However, Imam Khomeini Hospital has no air access, no quick access to emergency services other than the main entrance, and not enough signs.

Imam Khomeini Hospital does not have a pre-arranged place to store drugs and necessary equipment to establish a mobile hospital in emergency situations. In the study of Hosseini et al. in Razavi Hospital, a specific place was designated for storing essential goods in emergency conditions. Imam Reza Hospital had a drug depot, but no place to store essential goods for crisis management (1).

In terms of public access to downtown, Imam Khomeini Hospital is in a good location, but the heavy traffic and the lack of access to highways are the disadvantages. However, due to easy access to highways and the lack of traffic jams, Razavi Hospital in Mashhad was in a good location while it was not eligible due to the lack of access to urban rail transit. Besides, it did not have access to the first fastest highways, and having access to the second fastest highways was a disadvantage for the hospital because they had heavy traffic loads (1).

The parking lot in Imam Khomeini Hospital can hold about 400 cars, which is not adequate. The capacity of the parking lot in Mashhad's Razavi Hospital was 700 cars, and a vertical parking with 400 parking spaces was under construction, as one of the major problems of Mashhad's Imam Reza Hospital was inadequate parking spaces (1).

Too many intersections in the city slows traffic, therefore, traffic lights should be installed at all intersections around the hospital at a distance of 2000 meters, especially within a radius of 500 to $1000 \mathrm{~m}$. There are 3 intersections near Imam Khomeini Hospital and the distance between the intersection and the first entry is about $140 \mathrm{~m}$, which is much less than the standard distance (1).

\section{Conclusion}

All buildings, especially health care centers, need to comply with technical principles of design and construction to increase their safety. As it is not possible to strengthen all hospitals in the city simultaneously, Imam Khomeini Hospital was evaluated as a model with 16 indicators of passive defense based on the existing standards.

The results of the present study demonstrated that Imam Khomeini Hospital does not have a pre-arranged strategy to provide the safety of a hospital in natural and man-made disasters. After any unexpected disasters, the treatment process will be disrupted. Among the evaluated indicators, four indicators were in line with existing standards, and 12 indicators required some interventions to improve the hospital's performance at times of crisis.

Most of the passive defense studies were conducted in just some parts of a hospital, while in this study 16 safety indicators for hospital building were evaluated in terms of passive defense. In the study of Firozi et al. four major indicators related to the materials, building lifetime, the number of floors, and type of skeleton structure were evaluated (11).

Review of current status of Imam Khomeini Hospital showed that some indicators could be improved by interventions and they could be confirmed to passive defense measures. Since the Imam Khomeini Hospital covers an area of more than 40,000 square meters, air access can be easily made available by installing a helipad in open space and on the rooftop of new buildings. Moreover, other shortcomings can be overcome by establishing deep underground shelters, storing goods and vital equipment in safe places and underground shelters, relocating the police department to a farther location of more than 1000 meters away, expanding the green space around the hospital, and establishing a vertical parking inside or outside the hospital space.

\section{Acknowledgments}

The authors would like to show their gratitude to the esteemed staff of technical office at Urmia's Imam Khomeini Hospital who helped with data collection. There is no financial support for this project.

\section{Footnotes}

Authors' Contribution: Conceived and designed the experiments: Saeed Hosseinpoor; data collection: Shadi Nouriaghdam, Zohreh Ghaffarzadeh and Elahe Shakeri; writing the paper: Saeed Hosseinpoor, Shadi Nouriaghdam, Zohreh Ghaffarzadeh and Elahe Shakeri. All authors read and approved the final manuscript.

Conflict of Interests: The authors declare that there is no conflict of interest in the current research.

Funding/Support: There is no financial support for this project.

\section{References}

1. Hosseini SH, Seddighi A, Hosseini AH. [Pathology of Mashhad hospitals with emphasis on passive defense approach case study: Razavi and Emam Reza hospitals].J Geogr Soc Iran. 2014;12(42):211-38. Persian. 
2. Sullivant J.Strategies for protecting national critical infrastructure assets: A focus on problem-solving. New Jersey: John Wiley \& Sons; 2007. doi: $10.1002 / 9780470228371$.

3. Khayrabadi SAN. [Passive defense requirements in the design and construction of field hospitals with an emphasis on camouflage, Hiding and deceiving]. Congress of passive defense in science and engineering with an emphasis on camouflage, concealment and deception. Tehran. 2014. p. 1-17. Persian.

4. Hosseini AH, Asadi S, Bornafar M. [Evaluation of the structure Langrood city for passive defense planning]. J Geogr Sci. 2010;15(18):12949. Persian.

5. Shakiba Manesh A, Hashemi Fesharaki J. [Urban design from the perspective of passive defense]. Tehran: Bostan Hamid Press; 2011. Persian.

6. Schilling S, Fusco FM, De Iaco G, Bannister B, Maltezou HC, Carson G, et al. Isolation facilities for highly infectious diseases in Europe-a crosssectional analysis in 16 countries. PLoS One. 2014;9(10). e100401. doi: 10.1371/journal.pone.0100401. [PubMed: 25350843]. [PubMed Central: PMC4211666].

7. Road Research, Housing and Urban Development Research Center.
[National Regulations of Building]. 2nd ed. Tehran: Development Publishing; 2017. Persian.

8. Savadkoohifar S, Zokai Fateh J. [Passive defense considerations and crisis management in field emergency medical services in crisis situations]. Congress of passive defense in science and engineering with an emphasis on camouflage, concealment and deception. Urmia, Iran. 2014. p. 1-19. Persian.

9. Piri H, Hassan Nejad H, Fakhrabadi MA. [Prioritizing hospital for managing construction protecting against manmade threat].J Eng Constr Manag. 2016;1(1):33-6. Persian.

10. Khalooei A, Rabori MM, Nakhaee N. Safety condition in hospitals affiliated to Kerman University of Medical Sciences, 2010 [Safety condition in Hospitals Affiliated to Kerman University of Medical Sciences, 2010]. J Health Dev. 2013;2(3):192-202. Persian.

11. Firozi MA, Mohammadi Dehcheshmeh M, Nazarpour Dezaki R, Shojaean A. [The measuring of the structural vulnerability of hospitals from the passive defense point of view by FAHP (case study: Ahvaz metropolis)]. J Spat Plan. 2016;20(1):149-78. Persian. 